\title{
EFICÁCIA DAS RECOMENDAÇÕES DE ADUBAÇÃO PARA DIFERENTES EXPECTATIVAS DE PRODUTIVIDADE DE ARROZ IRRIGADO POR INUNDAÇÃO ${ }^{(1)}$
}

\author{
Silvio Aymone Genro Junior ${ }^{(2)}$, Elio Marcolin $^{(3)} \&$ Ibanor Anghinoni $^{(4)}$
}

\begin{abstract}
RESUMO
Em decorrência dos altos rendimentos de arroz irrigado por inundação, verificados nos últimos anos, e das respostas dessa cultura à adubação no Sul do Brasil, as recomendações de adubação foram flexibilizadas no sentido de atender a diferentes expectativas de produtividade. Como essas recomendações foram embasadas em poucos dados de pesquisa, o presente trabalho foi desenvolvido para avaliar a eficácia delas para o sistema de semeadura em solo seco nas regióes arrozeiras do RS. Foram conduzidos 13 experimentos de campo, quatro na safra 2004/2005 e nove na safra 2005/2006, com os seguintes tratamentos: 1 - Testemunha (sem adubação); 2- Recomendação de adubação para atingir produtividade até 6,0 $\mathrm{Mg} \mathrm{ha}^{-1}$; 3- Para atingir produtividade entre 6,0 e 9,0 $\mathrm{Mg} \mathrm{ha}^{-1}$; 4- Para atingir produtividade entre 9,0 e 12,0 $\mathrm{Mg} \mathrm{ha}^{-1}$; e 5- Para atingir produtividade maior que $12,0 \mathrm{Mg} \mathrm{ha}^{-1}$. Os tratamentos 2, 3 e 4 constituem as recomendações de adubação para o arroz irrigado no Sul do Brasil. As doses foram definidas em função dos índices de fertilidade de cada local, e os tratamentos, distribuídos em blocos ao acaso. As indicações de adubação para o arroz irrigado no sistema de semeadura em solo seco, apesar de resultarem em incremento relevante de produtividade (média de 3,2 $\mathrm{Mg} \mathrm{ha}^{-1}$ ), não atenderam às respectivas expectativas, pois variaram com as condições edafoclimáticas de cada local.
\end{abstract}

Termos de indexação: nitrogênio, fósforo, potássio, semeadura em solo seco.

(1) Projeto financiado pelo Instituto Rio-Grandense do Arroz - IRGA. Recebido para publicação em maio de 2008 e aprovado em julho de 2010 .

(2) Engenheiro-Agrônomo, M.Sc., Pesquisador do Instituto Rio-Grandense do Arroz - IRGA. Av. Bonifácio Carvalho Bernardes 1494, CEP 94930-030 Cachoeirinha (RS). E-mail: genrojr@yahoo.com.br

(3) Engenheiro-Agrônomo, M.Sc., Pesquisador do Instituto Rio-Grandense do Arroz (IRGA). E-mail: elio-marcolin@irga.rs.gov.br

(4) Professor do Departamento de Solos, Universidade Federal do Rio Grande do Sul - UFRGS. Av. Bento Gonçalves 7712 , CEP 91540-000 Porto Alegre (RS). Bolsista do CNPq. E-mail: ibanghi@ufrgs.br 


\title{
SUMMARY: EFFICACY OF FERTILIZER RECOMMENDATIONS FOR DIFFERENT YIELD EXPECTATIONS OF FLOODED RICE
}

\begin{abstract}
As a result of high flooded rice yields obtained in more recent years and the high crop response to fertilization in southern Brazil, fertilizer recommendations were flexibilized to meet different yield expectations. As these recommendations were poorly supported by research results, this study was conducted to evaluate the efficacy of these recommendations for the dryseeded rice system in the rice cultivation regions of the State. Thirteen field experiments were conducted at nine locations: four in the 2004/2005 and nine in the 2005/2006 growing seasons with the following treatments: 1 . Control (without fertilization); 2. Recommendation to acchieve yield up to $6.0 \mathrm{Mg} \mathrm{ha}^{-1}$; 3. For yields of $6.0-9.0 \mathrm{Mg} \mathrm{ha}^{-1}$; 4. For yields of 9.0 $12.0 \mathrm{Mg} \mathrm{ha}^{-1}$ and 5. For yields of more than $12.0 \mathrm{Mg} \mathrm{ha}^{-1}$. Treatments 2, 3, and 4 represent the official regional fertilizer recommendations for flooded rice. The applied fertilizer rates were defined by the soil fertility status of each location, and treatments were distributed in randomized blocks. Fertilizer recommendations for dry-seeded flooded rice, in spite of resulting in relevant and consistent yield increases (average of $3.2 \mathrm{Mg} \mathrm{ha}^{-1}$ ), did not achieve the expected yields, which depend on the soil and climate conditions of each location.
\end{abstract}

Index terms: nitrogen, phosphorus, potassium; dry-seeded rice.

\section{INTRODUÇÃO}

A lavoura arrozeira no Estado do Rio Grande do Sul tem ocupado, nos últimos anos, uma área de aproximadamente 1,0 milhão de hectares (IRGA, 2008) dos seus 5.4 milhões aptos ao cultivo com essa cultura (Pinto et al., 2004). Na safra 2006/07, a produção total de arroz nesse Estado foi de 6,49 milhões de toneladas de grãos, o que equivalia a $53 \%$ da produção brasileira (CONAB, 2007).

Houve aumento significativo na produtividade média dessa cultura no Rio Grande do Sul ao longo dos anos, passando de menos de 3,30 Mg ha-1, em 1970, para $6,88 \mathrm{Mg} \mathrm{ha}^{-1}$, na safra 2006/07 (IRGA, 2008). Esse aumento ocorreu inicialmente pela troca gradativa dos cultivares de porte alto pelos de porte médio e, depois, pelos de porte baixo - tipo moderno, que são mais eficientes no aproveitamento da radiação solar e mais responsivos ao manejo (Menezes et al., 2004; Terres et al., 2004).

A resposta do arroz ao $\mathrm{N}$ está muito relacionada aos fatores climáticos, ao tipo de planta e ao manejo. Por essas razões, no Sul do Brasil, a resposta da cultura, mesmo dos cultivares do tipo moderno, tem sido variável: assim, de 31 experimentos, em seis não houve resposta, em cinco a resposta foi negativa e em 20 foi positiva, sendo cinco de forma linear e 15 de forma quadrática (Scivittaro \& Machado, 2004). A análise agregada de trabalhos de resposta do arroz irrigado com semeadura em solo seco à aplicação de fósforo no RS (21 experimentos - Vahl, 2004) e no sistema pré-germinado em SC (55 experimentos Machado \& Pottker, 1979) mostra que a dose de P foi relativamente pequena e raramente superior a $60 \mathrm{~kg}$ de $\mathrm{P}_{2} \mathrm{O}_{5} \mathrm{ha}^{-1}$. A resposta do arroz ao potássio também foi pequena, com a dose se situando entre 40 e $50 \mathrm{~kg} \mathrm{ha}^{-1}$ de $\mathrm{K}_{2} \mathrm{O}$, mesmo em solos com teores enquadrados como baixos, na análise conjunta de 18 experimentos no sistema de semeadura em solo seco (Machado, 1993) e de 29 experimentos no sistema pré-germinado (Machado \& Pottker, 1979) - mesmo com a utilização de cultivares de porte baixo.

As recomendações oficiais de adubação para essa cultura (Mielniczuk et al., 1969; UFRGS, 1973; Manual, 1981; Siqueira et al., 1987; CFS RS/SC, 1995) também foram sendo reformuladas com a evolução do potencial produtivo dos cultivares, a partir da recomendação de $110 \mathrm{~kg}$ ha-1 de $\mathrm{N}+\mathrm{P}_{2} \mathrm{O}_{5}+\mathrm{K}_{2} \mathrm{O}$, em meados da década de 1960 , para $210 \mathrm{~kg} \mathrm{ha}^{-1}$, em 1987, não havendo alteração na revisão de 1995 (Anghinoni et al., 2005). No entanto, a utilização recente (a partir da safra 2002/03) do manejo integrado da cultura resultou na obtenção de alto rendimento de arroz (de 8 a $10 \mathrm{Mg} \mathrm{ha}^{-1}$ ) em lavouras de todas as regiões arrozeiras do RS (Menezes et al., 2004) e criou a necessidade de se retomar a questão da resposta do arroz à adubação para atender às demandas desse novo cenário. Assim, foram elaboradas novas recomendações de adubação para o arroz irrigado (CFQS RS/SC, 2004; SOSBAI, 2005), que passaram a considerar diferentes expectativas de produtividade e de doses mais elevadas de nutrientes: $\mathrm{N}$ (de 90 para $120 \mathrm{~kg} \mathrm{ha}^{-1}$ ), $\mathrm{P}_{2} \mathrm{O}_{5}\left(60\right.$ para $\left.90 \mathrm{~kg} \mathrm{ha}^{-1}\right), \mathrm{K}_{2} \mathrm{O}\left(60\right.$ para $\left.90 \mathrm{~kg} \mathrm{ha}^{-1}\right) \mathrm{e}$ no total (210 para $300 \mathrm{~kg} \mathrm{ha}^{-1}$ ), no caso da faixa de interpretação baixo nas análises de solo e para expectativas de produtividade acima de $9,0 \mathrm{Mg} \mathrm{ha}^{-1}$ de grãos. Para expectativas de menor produtividade (até 6,0 e 6,0 a 9,0 $\mathrm{Mg} \mathrm{ha}^{-1}$ ) ou enquadramento das faixas de maior fertilidade (médio, alto e muito alto), as recomendações desses nutrientes são menores, conforme verificado nas tabelas de recomendação (CFQS RS/ SC, 2004; SOSBAI, 2005). Mesmo considerando que as recomendações de adubação, por seus princípios e 
prática, tenham caráter genérico e certa flexibilidade, houve necessidade de verificar sua adequação nas diferentes regiões arrozeiras do $\mathrm{RS}$, especialmente em lavouras sob cultivo contínuo. Isso porque os experimentos que historicamente forneceram o suporte para as recomendações foram, na sua maioria, instalados em somente duas classes de solo (Planossolo e Gleissolo) e, em muitos casos, não atendendo às recomendações técnicas do manejo integrado da cultura. Além disso, as recomendações adotadas a partir de 2004, para três faixas de produtividade no sistema de semeadura em solo seco, foram elaboradas com base em poucos dados de pesquisa (Genro Jr. et al., 2005) e pouca representatividade das condições edafoclimáticas das regiões arrozeiras do Estado.

Devido ao exposto, o presente trabalho foi desenvolvido com o objetivo de verificar a eficácia das recomendações de adubação para diferentes produtividades de arroz nas condições edafoclimáticas das regiões arrozeiras do Estado do Rio Grande do Sul.

\section{MATERIAL E MÉTODOS}

Foram conduzidos 13 experimentos de campo, sendo quatro na safra 2004/05 e nove na de 2005/06, em diferentes regiões arrozeiras do Estado: na Planície Costeira Externa (4), na Planície Costeira Interna (2), na Depressão Central (3), na Fronteira Oeste (2) e na Campanha (2). A localização e a classificação dos solos encontram-se no quadro 1.
Em todos os locais, foi utilizado o delineamento experimental em blocos ao acaso com cinco tratamentos, sendo: 1- Testemunha (sem adubação); 2- Recomendação de adubação para atingir produtividade até $6,0 \mathrm{Mg} \mathrm{ha}^{-1}$; 3- Para atingir produtividade entre 6,0 e $9,0 \mathrm{Mg} \mathrm{ha}^{-1}$; 4- Para atingir produtividade entre 9,0 e $12,0 \mathrm{Mg}^{-1}$; e 5- Para atingir produtividade maior que $12,0 \mathrm{Mg} \mathrm{ha}^{-1}$, com duas repetições. Os tratamentos 2, 3 e 4 constituem as recomendações de adubação para o arroz irrigado no Sul do Brasil para o sistema de semeadura em solo seco, conforme consta em CFQS RS/SC (2004) e SOSBAI (2005). As doses dos adubos para cada tratamento e local foram estabelecidas em função dos índices de fertilidade de cada local (Quadro 2). Os tratamentos foram ajustados para um incremento de $3,0 \mathrm{Mg} \mathrm{ha}^{-1}$ na produtividade de grãos, tomando como referência o centro da faixa. O tamanho das parcelas variou conforme a disponibilidade de área: 6 x $10 \mathrm{~m}$ em Cachoeira do Sul, 6 x $18 \mathrm{~m}$ em Cachoeirinha e 10 x 20 m em Santo Antônio da Patrulha e Camaquã, na safra 2004/2005. Na safra 2005/2006, o tamanho das parcelas foi de $10 \times 20 \mathrm{~m}$ em todos os locais, com exceção de Cachoeira do Sul (6 x 10 m) e Cachoeirinha $(6 \times 18 \mathrm{~m})$.

O P, na forma de superfosfato triplo, e o $\mathrm{K}$, na forma de cloreto de potássio, foram aplicados na base por ocasião da semeadura. O N, na forma de ureia, foi aplicado na base, variando de 5,0 a $20 \mathrm{~kg} \mathrm{ha}^{-1}$, para expectativas de produtividade de até 6,0 a mais de $12,0 \mathrm{Mg} \mathrm{ha}{ }^{-1}$, respectivamente, e o restante, em duas aplicações de cobertura, sendo $2 / 3$ em V3/V4 e o

Quadro 1. Localização, classificação, teor de argila e de cátions trocáveis dos solos utilizados

\begin{tabular}{|c|c|c|c|c|c|c|}
\hline \multirow{2}{*}{ Local } & \multirow{2}{*}{$\begin{array}{l}\text { Coordenadas } \\
\text { geográficas }\end{array}$} & \multirow{2}{*}{ Classificação(1) } & \multirow{2}{*}{ Argila } & \multicolumn{3}{|c|}{ Cations trocáveis ${ }^{(2)}$} \\
\hline & & & & $\mathbf{C a}$ & Mg & $\mathrm{Al}$ \\
\hline & & & $\mathrm{g} \mathrm{kg}-1$ & \multicolumn{3}{|c|}{$\mathrm{cmol}_{\mathrm{c}} \mathrm{dm}^{-3}$} \\
\hline Santo A. Patrulha & $\begin{array}{l}30^{\circ} 02^{\prime} 06,77^{\prime \prime} \mathrm{S} \\
50^{\circ} 31^{\prime} 48,35^{\prime \prime} \mathrm{O}\end{array}$ & Planossolo Háplico eutrófico arênico & 140 & 4,6 & 2,1 & 0,2 \\
\hline Cachoeira do Sul & $\begin{array}{l}30 \circ 13,10,88^{\prime \prime} \mathrm{S} \\
52^{\circ} 57^{\prime} 12,87 ” \mathrm{O}\end{array}$ & Planoss olo Háplico eutrófico arênico & 220 & 2,1 & 1,3 & 0,6 \\
\hline Camaquã & $\begin{array}{l}30^{\circ} 52^{\prime} 09,38^{\prime \prime} \mathrm{S} \\
51^{\circ} 47^{\prime} 37,47^{\prime \prime} \mathrm{O}\end{array}$ & Planossolo Háplico eutrófico arênico & 150 & 4,3 & 2,0 & 0,1 \\
\hline Restinga Seca & $\begin{array}{l}29 \circ 40^{\prime} 11,13^{\prime \prime} \mathrm{S} \\
53 \circ 21^{\prime} 22,30 " \mathrm{O}\end{array}$ & Gleissolo Háplico distrófico típico & 160 & 1,8 & 0,5 & 1,7 \\
\hline Cachoeirinha & $\begin{array}{l}29 \circ 56,38,57 ” \mathrm{~S} \\
51^{\circ} 07^{\prime} 13,20 ” \mathrm{O}\end{array}$ & Gleissolo Háplico distrófico típico & 200 & 1,8 & 0,7 & 0,4 \\
\hline Uruguaiana 1 & $\begin{array}{l}30^{\circ} 01^{\prime} 46,07 ” \mathrm{~S} \\
56^{\circ} 36^{\prime} 34,89^{\prime \prime} \mathrm{O}\end{array}$ & $\begin{array}{l}\text { Chernossolo Ebânico carb . } \\
\text { vertissólico }\end{array}$ & 250 & 12,2 & 6,1 & 0 \\
\hline Uruguaiana 2 & $\begin{array}{l}29^{\circ} 49^{\prime} 44,83^{\prime \prime} \mathrm{S} \\
57^{\circ} 05^{\prime} 58,28^{\prime \prime} \mathrm{O}\end{array}$ & Neossolo Litólico eutrófico típico & 180 & 7,5 & 3,2 & 0 \\
\hline D. Pedrito 1 & $\begin{array}{l}30^{\circ} 56^{\prime} 00,67^{\prime \prime} \mathrm{S} \\
54^{\circ} 45^{\prime} 36,35^{\prime \prime} \mathrm{O}\end{array}$ & $\begin{array}{l}\text { Planossolo Háplico eutrófico } \\
\text { vertissólico }\end{array}$ & 230 & 12,3 & 4,1 & 0 \\
\hline D. Pedrito 2 & $\begin{array}{l}30 \circ 44^{\prime} 12,92 " \mathrm{~S} \\
54^{\circ} 50^{\prime} 08,14^{\prime \prime} \mathrm{O}\end{array}$ & $\begin{array}{l}\text { Chernossolo Argil. órtico } \\
\text { vertissólico }\end{array}$ & 270 & 25,4 & 7,3 & 0 \\
\hline
\end{tabular}

(1) Conforme Embrapa (2006) e Streck et al. (2008). ${ }^{(2)} \mathrm{KCl} \mathrm{1,0} \mathrm{mol} \mathrm{L}^{-1}$. 
Quadro 2. Índices de fertilidade dos solos utilizados e sua interpretação(1)

\begin{tabular}{|c|c|c|c|c|}
\hline \multirow{2}{*}{ Local } & \multicolumn{3}{|c|}{ Índice fertilidade/interpretação ${ }^{(1)}$} & \multirow{2}{*}{$\mathrm{CTC}_{\mathrm{pH} \mathrm{7,0}}$} \\
\hline & Mat. orgânica & P disponível ${ }^{(2)}$ & K disponível ${ }^{(2)}$ & \\
\hline & $\%$ & $r$ & - & $\mathrm{cmol}_{\mathrm{c}} \mathrm{dm}^{-3}$ \\
\hline Santo A. Patrulha & 1,3 Baixo & 8,2 Alto & 59 Médio & 7,0 Médio \\
\hline Cachoeira do Sul & 1,4 Baixo & 13,4 Muito alto & 43 Médio & 6,7 Médio \\
\hline Camaquã & 1,8 Baixo & 10,2 Alto & 62 Alto & 9,2 Médio \\
\hline Restinga Seca & 1,4 Baixo & 8,5 Alto & 47 Médio & 6,7 Médio \\
\hline Cachoeirinha & 1,1 Baixo & 6,7 Alto & 37 Médio & 7,5 Médio \\
\hline Uruguaiana 1 & 4,0 Médio & 12,8 Muito alto & 120 Alto & 23,0 Alto \\
\hline Uruguaiana 2 & 3,2 Médio & 5,1 Médio & 74 Alto & 15,6 Alto \\
\hline D. Pedrito 1 & 2,3 Baixo & 16,1 Muito alto & 139 Muito alto & 19,8 Alto \\
\hline D. Pedrito 2 & 4,6 Médio & 6,7 Médio & 122 Muito alto & 36,5 Alto \\
\hline
\end{tabular}

${ }^{(1)}$ Conforme CQFS RS/SC (2004). ${ }^{(2)}$ Método Mehlich-1.

restante (1/3) na diferenciação do primórdio floral (DPF).

Os cultivares e as datas de semeadura na safra 2004/2005 foram: IRGA 422CL, em Santo Antonio da Patrulha (22/10/2004); e IRGA 417, em Cachoeira do Sul (26/10/2004), Camaquã (08/11/2004) e Cachoeirinha (20/11/2004). A densidade de semeadura nessa safra foi de $120 \mathrm{~kg} \mathrm{ha}^{-1}$ de semente. Na safra 2005/06, os cultivares utilizados foram: BR-IRGA 409, em Santo Antônio da Patrulha (4/10/2005); IRGA 417, Uruguaiana 2 (21/10/2005), Dom Pedrito 1 (23/10/ 2005), Dom Pedrito 2 (3/11/2005), Cachoeira do Sul (5/11/2005), Cachoeirinha (12/11/2005) e Restinga Seca (23/11/2005); e IRGA 420, em Uruguaiana 1 (21/10/ 2005). A densidade foi de $100 \mathrm{~kg} \mathrm{ha}^{-1}$ de sementes. Todos os cultivares utilizados são de porte baixo, de ciclo precoce e de potencial produtivo elevado.

O manejo da cultura seguiu as indicações constantes nas Recomendações Técnicas da Pesquisa para o Sul do Brasil (SOSBAI, 2003, 2005), que se constituem no Manejo Integrado da cultura. Esse manejo inclui recomendações para a sistematização do terreno, o preparo antecipado do solo, a época de semeadura, a densidade de sementes, a época de entrada da água e da adubação nitrogenada em cobertura, o controle de invasoras, de pragas e de doenças e a altura da lâmina de água. Quanto ao controle de plantas daninhas, predominantemente plantas dos gêneros Echinicloa sp., Aeschynomene sp. e Cyperus sp., utilizou-se herbicida com o ingrediente ativo Penoxsulam, na dose de $200 \mathrm{~mL} \mathrm{ha}^{-1}$. Para o controle de Oryza sativa (arroz-vermelho), utilizou-se o herbicida com ingrediente ativo imazapic + imazethapyr, na dose de 1,0 L ha' ${ }^{-1}$. A colheita de grãos foi em área útil de $4 \times 5=20 \mathrm{~m}^{2}$, nas duas safras. A produtividade de grãos foi determinada após secagem, sendo o teor de umidade corrigido para $13 \%$.

Foi efetuada a análise da variância $(p<0,05)$, com a aplicação do teste de Tukey $(p<0,05)$ para a diferenciação entre as médias de rendimento de grãos de arroz, obtidas em relação ao esperado em função da adubação para diferentes expectativas de produtividade. Nessa análise, foram utilizados os resultados médios de cada local, repetidos no tempo (safras) e no espaço (locais).

\section{RESULTADOS E DISCUSSÃO}

A fim de verificar a eficácia das recomendações de adubação para as três expectativas de produtividade, foi feita, inicialmente, uma avaliação conjunta dos 13 experimentos nas duas safras (Figura 1). Comparando os tratamentos que obtiveram os maiores rendimentos com o tratamento referência (sem adubação), observase incremento médio de $3,2 \mathrm{Mg}_{\mathrm{ha}}{ }^{-1}$, o que confirma a magnitude das respostas que originaram as recomendações para diferentes expectativas de produtividade (Genro Junior et al., 2005) e os elevados rendimentos das lavouras conduzidas dentro do manejo integrado da cultura (Menezes et al., 2004).

Na comparação entre as produtividades obtidas e as esperadas (Figura 1), houve similaridade para a faixa intermediária, estando a média obtida dentro da respectiva faixa $\left(6,0-9,0 \mathrm{Mg} \mathrm{ha}^{-1}\right)$. No entanto, isso não ocorreu para as demais expectativas: a produtividade média obtida $\left(8,1 \mathrm{Mg} \mathrm{ha}^{-1}\right)$ para a menor faixa de expectativas foi maior em relação à esperada (até $\left.6,0 \mathrm{Mg} \mathrm{ha}^{-1}\right)$; e a produtividade obtida $\left(8,8 \mathrm{Mg} \mathrm{ha}^{-1}\right)$ para a maior faixa, além de não atingir o valor inferior da respectiva faixa $\left(9,0 \mathrm{Mg} \mathrm{ha}^{-1}\right)$, foi menor do que o centro de classe $\left(10,5 \mathrm{Mg} \mathrm{ha}^{-1}\right)$, tomado como referência. O tratamento com maior adubação (T5) foi utilizado para verificação da resposta potencial da cultura à adubação. Assim, o menor rendimento obtido neste tratamento em relação ao esperado devese à resposta quadrática das culturas à aplicação de doses crescentes de adubo, enquanto a expectativa tomada como referência para esse tratamento $\left(12,0 \mathrm{Mg} \mathrm{ha}^{-1}\right)$ foi uma projeção linear e, por isso, superestimada. 


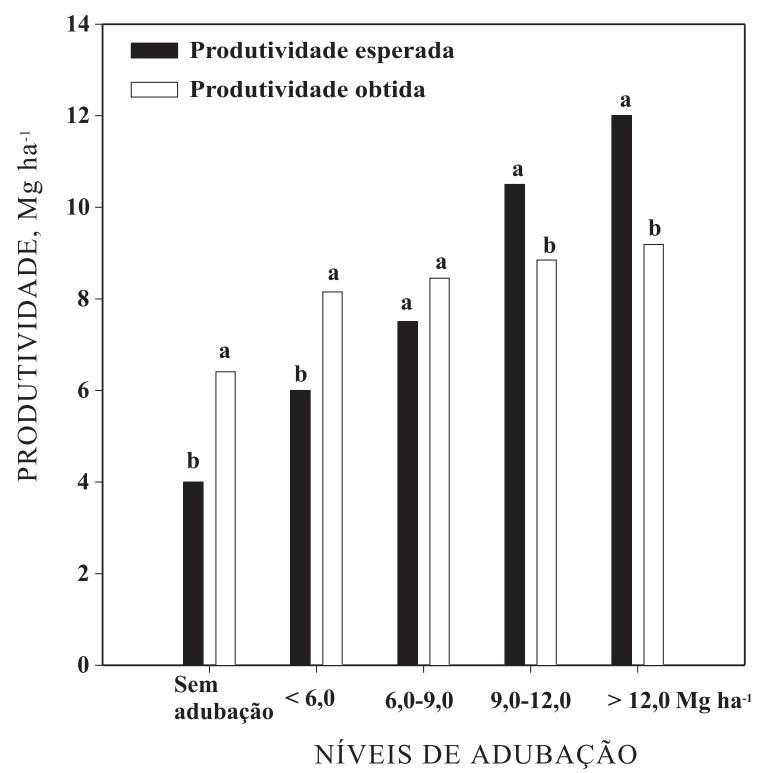

Figura 1. Produtividade de grãos de arroz irrigado esperada e obtida em função da adubação para diferentes expectativas de produtividade. Barras seguidas de mesma letra dentro de cada nível de adubação não diferem pelo teste de Tukey $(p<0,05)$. Média de 13 experimentos em diferentes cultivares, locais e safras (2004/2006).

A produtividade média das parcelas testemunhas, sem adubação $\left(6,5 \mathrm{Mg} \mathrm{ha}^{-1}\right)$, foi superior àquela tomada como referência (Figura 1), no estabelecimento das recomendações (CQFS RS/SC, 2004; SOSBAI, 2005). Essa diferença deve-se, provavelmente, a dois fatos principais: ao baixo rendimento utilizado como referência no tratamento sem adubação $\left(4,0 \mathrm{Mg} \mathrm{ha}^{-1}\right)$, oriundo da pesquisa existente (Scivittaro \& Machado, 2004) em somente duas classes de solos (Planossolos háplicos e Gleissolos háplicos), de baixo potencial produtivo (Streck et al., 2008); e à adoção, no presente trabalho, dos novos preceitos no manejo do solo e da cultura (Menezes et al., 2004).

A utilização de Chernossolos (2), Neossolo eutrófico (1) e Planossolo vertissólico, em adição aos Planossolos e Gleissolos háplicos, no presente trabalho (Quadro 1), permitiu a diferenciação do comportamento do arroz irrigado, formando dois grupos de solos em relação ao potencial produtivo de arroz irrigado: (a) PlanossolosGleissolos e (b) dos demais solos, sendo este o grupo mais produtivo (Figura 2). Os Planossolos e Gleissolos são originários de sedimentos arenosos, ocorrem nas regiões das Planícies Costeiras e da Depressão Central e possuem, de modo geral, menores teores de matéria orgânica, de nutrientes disponíveis e de argila (Quadros 1 e 2). Os solos do outro grupo (ChernossolosNeossolo-Planossolo vertissólico) são originários de basalto e de siltitos/argilitos, ocorrem nas regiões da Fronteira Oeste e da Campanha, são menos desenvolvidos e contêm argila do tipo esmectita, originando solos com alta capacidade de troca de cátions (Quadro 2). Este é um atributo utilizado pela CQFS RS/SC (2004) para diferenciar grupos de solos para o estabelecimento de níveis críticos e recomendação de potássio, que também foi diferenciado entre os dois grupos de solos, variando de 6,7 a 9,5 (média 7,2) $\mathrm{cmol}_{\mathrm{c}} \mathrm{dm}^{-3}$ nos Planossolos-Gleissolos e de 15,6 a 36,5 (média 23,7) $\mathrm{cmol}_{\mathrm{c}} \mathrm{dm}^{-3}$ no outro grupo (Quadro 2). Nessa análise (Figura 2), verifica-se que o rendimento médio das testemunhas do grupo dos Planossolos-Gleissolos háplicos foi menor do que o do grupo dos demais solos, porém ainda superior ao do tratamento testemunha (sem adubação), tomado como referência. Isso também ocorreu no tratamento 2 , com produtividade esperada de até $6,0 \mathrm{Mg} \mathrm{ha}^{-1}$. Similaridade de produtividade, entre a observada e a esperada, somente foi obtida para o grupo dos Planossolos-Gleissolos háplicos para a faixa de produtividade intermediária $\left(6,0-9,0 \mathrm{Mg} \mathrm{ha}^{-1}\right)$. Para as expectativas de produtividade de 9,0 a $12,0 \mathrm{Mg} \mathrm{ha}^{-1}$ (tratamento 4), embora a produtividade obtida nos Chernossolos-Neossolo-Planossolo vertissólico tenha sido superior à dos Planossolos-Gleissolos háplicos, ela ainda foi menor do que a esperada (Figura 2). Dessa forma, verifica-se que a subdivisão dos solos em dois grupos (Figura 2), apesar de demonstrar potenciais de produtividade diferenciados (em torno de $2,7 \mathrm{Mg} \mathrm{ha}^{-1}$ ) e ganhos médios similares pela adubação, não contribuiu para melhorar a eficácia das recomendações de adubação para diferentes expectativas de produtividade, em relação à sua avaliação conjunta (Figura 1).

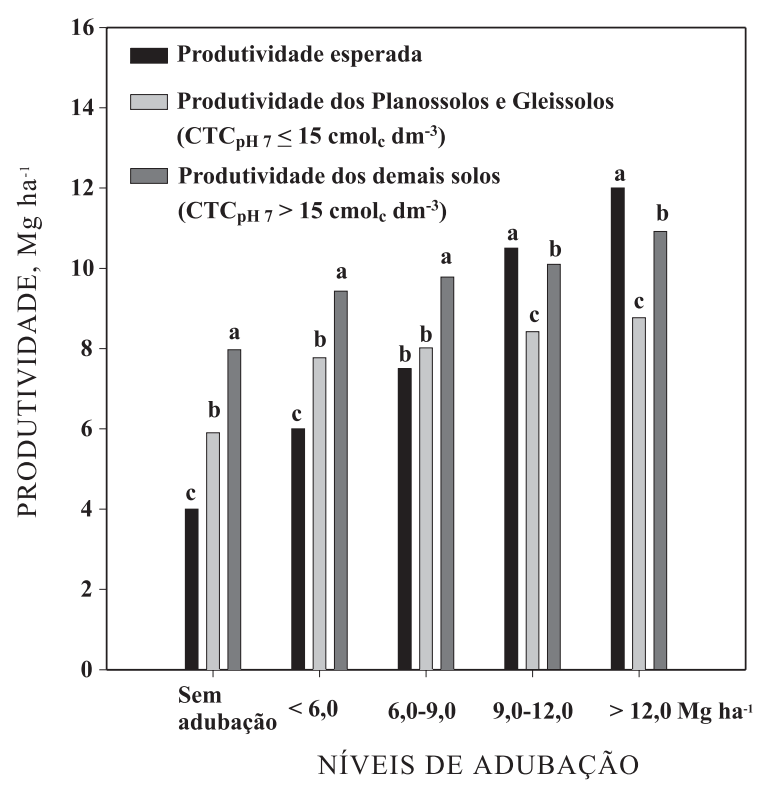

Figura 2. Produtividade de grãos de arroz irrigado em função da adubação para diferentes expectativas de produtividade em diferentes grupos de solos. Barras seguidas de mesma letra dentro de cada nível de adubação não diferem pelo teste de Tukey $(p<0,05)$. Média de 13 experimentos em diferentes cultivares, locais $\mathrm{e}$ safras (2005/06). 
A razão da disparidade, que ocorreu entre as produtividades obtidas em relação às esperadas com as recomendações, deve-se ao potencial produtivo de arroz de cada local sem adição de adubo (testemunha). Essa produtividade foi muito variável nos diferentes locais: de 4,2 Mg ha-1 em Planossolo Háplico Eutrófico arênico a 9,1 Mg ha-1 em Chernossolo Argilúvico órtico vertissólico (Quadro 4) e deve estar relacionada às condições edafoclimáticas. Os ganhos em produtividade pela adubação foram relevantes e consistentes, concentrando-se ao redor de $3,2 \mathrm{Mg}^{-1}$, variando, $^{-1}$ porém, de 2,1 $\mathrm{Mg} \mathrm{ha}^{-1}$, no Chernossolo Ebânico carbonático vertissólico, a 3,9 $\mathrm{Mg} \mathrm{ha}^{-1}$, no Planossolo Háplico Eutrófico vertissólico, na safra 2005/2006, em ambos os casos (Quadro 4). Não se espera que tenha havido influência significativa dos diferentes cultivares utilizados, pois todos são do tipo moderno e de alto potencial produtivo (Terres et al., 2004). Dos 13 experimentos, em 10 foi utilizado o cultivar IRGA 417 e, em um, o IRGA CL 422 (mutante do IRGA 417), o IRGA 420 e o BR IRGA 410. Esperava-se que os Planossolos-Gleissolos háplicos tivessem maior incremento de resposta em relação ao outro grupo de solos. No entanto, isso não está evidenciado nos dados do quadro 4, uma vez que tanto o menor como o maior incremento foram obtidos no grupo dos CambissolosNeossolo-Planossolo vertissólico e na mesma safra (2005/06).

As doses de $\mathrm{N}, \mathrm{P}_{2} \mathrm{O}_{5}$ e $\mathrm{K}_{2} \mathrm{O}$ que resultaram no rendimento máximo (Quadro 4) foram maiores do que as recomendadas (CQFS RS/SC, 2004; SOSBAI, 2005) para alta produtividade $\left(>9,0 \mathrm{Mg}^{-1}\right)$, considerando as faixas de interpretação dos valores de análise dos solos utilizados no presente trabalho (Quadro 3). O ganho em produtividade de arroz com essa adubação, média de 3,2 $\mathrm{Mg}_{\mathrm{ga}}{ }^{-1}$ de grãos, é muito maior que seu custo, equivalente a $1,0 \mathrm{Mg} \mathrm{ha}^{-1}$ de grãos, considerando-se os valores vigentes na colheita da safra 2005/06 (Agrolink, 2007), o que resulta em um ganho líquido pela adubação equivalente a $2,0 \mathrm{Mg} \mathrm{ha}^{-1} \mathrm{de}$ grãos de arroz.
A grande e consistente resposta do arroz irrigado à adubação, verificada no presente trabalho, encontra suporte em trabalhos conduzidos no sistema de semeadura em solo seco (Lopes et al., 1999; Scivittaro et al., 2003; Scivittaro \& Machado, 2004; Vahl, 2004). Assim, quando houve, nesses trabalhos, resposta quadrática do arroz ao $\mathrm{N}$, o rendimento máximo ocorreu com a aplicação entre 66 e $126 \mathrm{~kg} \mathrm{ha}^{-1}$. A magnitude dessa resposta foi dependente do grau de infestação por invasoras, especialmente do arroz-vermelho, do histórico de cultivo, da época de semeadura, da eficiência da irrigação e da própria fonte fertilizante. As doses desse nutriente para o rendimento máximo de arroz (Quadro 4), apesar de serem maiores do que aquelas recomendadas para alta produtividade, são menores do que as recomendadas no Mississipi, EUA, que variam de 170 a $200 \mathrm{~kg} \mathrm{ha}^{-1}$ (Walker \& Street, 2003), em função do tipo de solo, e situadas dentro da faixa de 100 a $200 \mathrm{~kg} \mathrm{ha}^{-1}$, recomendadas em Arkansas, EUA (Norman et al., 2002) e na Austrália (Ricecheck, 2007), dependendo, em todos os casos, do histórico da área. A razão dessa menor recomendação no Sul do Brasil pode ter sido a opção pelo desenvolvimento de cultivares predominantemente de ciclo precoce (Terres et al., 2004). Estes, apesar de produtivos, apresentam menor potencial do que os de ciclo tardio, que são também mais responsivos à adubação nitrogenada, especialmente se cultivados no sistema pré-germinado, em que a eficiência desse nutriente é menor.

A resposta média do arroz irrigado à adição de $\mathrm{P}$ (Quadro 4) é similar ao que ocorre em outras regiões do Brasil e do mundo, que é raramente superior a 60 $\mathrm{kg}$ de $\mathrm{P}_{2} \mathrm{O}_{5}$ ha $^{-1}$ (Vahl, 2004). A resposta média à aplicação de $\mathrm{K}$ (62 $\mathrm{kg} \mathrm{ha}^{-1}$ - Quadro 4) é um pouco superior àquela verificada na análise conjunta de 18 experimentos no sistema de semeadura em solo seco do Rio Grande do Sul (Machado, 1983), que foi entre 40 e $50 \mathrm{~kg}$ de $\mathrm{K}_{2} \mathrm{O} \mathrm{ha}{ }^{-1}$. Mesmo que se considere o aumento do suprimento desse nutriente pela difusão e pelo deslocamento de $\mathrm{K}^{+}$por $\mathrm{NH}_{4}{ }^{+}, \mathrm{Fe}^{2+} \mathrm{e} \mathrm{Mn}^{2+}$, pelo alagamento e pela possível liberação de $\mathrm{K}$ da fração

Quadro 3. Quantidades de nutrientes aplicadas ${ }^{(1)}$ em função das faixas de interpretação dos teores de nutrientes nos solos (Quadro 2) para as diferentes expectativas de produtividade

\begin{tabular}{|c|c|c|c|c|c|c|}
\hline \multirow{2}{*}{ Índice de fertilidade } & \multirow{2}{*}{ Interpretação } & \multicolumn{5}{|c|}{ Tratamento de adubação/produtividade $\left(\mathrm{Mgha}^{-1}\right)$} \\
\hline & & Testemunha & $<6,0$ & 6,0 a 9,0 & $9,0-12,0$ & $>12,0$ \\
\hline & & & & $-\mathrm{N}-\mathrm{kg}$ ha & & \\
\hline \multirow[t]{3}{*}{ Matéria orgânica } & Baixo & 0 & 60 & 90 & 120 & 150 \\
\hline & Médio & 0 & 50 & 80 & 110 & 140 \\
\hline & Médio & 0 & 40 & $\begin{array}{c}\mathrm{P}_{2} \mathrm{O}_{5}-\mathrm{kg} \text { ha } \\
55\end{array}$ & 70 & \\
\hline \multirow[t]{2}{*}{ Fósforo disponível ${ }^{(2)}$} & Alto/Muito alto & 0 & 20 & 35 & 50 & 65 \\
\hline & & & & $\mathrm{K}_{2} \mathrm{O}-\mathrm{kg}$ ha & & \\
\hline \multirow[t]{2}{*}{ Potássio disponível(2) } & Médio & 0 & 40 & 50 & 60 & 70 \\
\hline & Alto/Muito alto & 0 & 20 & 30 & 40 & 50 \\
\hline
\end{tabular}

${ }^{(1)}$ Segundo CQFS RS/SC (2004). ${ }^{(2)}$ Mehlich-1. 
Quadro 4. Produtividade de grãos de arroz e seu incremento máximo e as respectivas doses de nutrientes em diferentes safras e locais do Rio Grande do Sul

\begin{tabular}{|c|c|c|c|c|c|c|c|c|}
\hline \multirow{2}{*}{ Local } & \multirow{2}{*}{ Safra } & \multicolumn{3}{|c|}{ Produtividade } & \multirow{2}{*}{ Tratamento } & \multicolumn{3}{|c|}{ Dose produtividade máxima } \\
\hline & & Test. & Máxima & Incremento & & $\mathbf{N}$ & $\mathbf{P}_{2} \mathbf{O}_{5}$ & $\mathrm{~K}_{2} \mathrm{O}$ \\
\hline & & 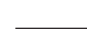 & $-\mathrm{Mg} \mathrm{ha}^{-}$ & - & & - & $\mathrm{kg} \mathrm{ha}^{-1}$ & - \\
\hline \multirow[t]{2}{*}{ Camaquã } & $2004 / 05$ & 4,2 & 7,4 & 3,2 & $\mathbf{T} \mathbf{4}^{(2)}$ & 120 & 50 & 60 \\
\hline & $2005 / 06$ & 4,4 & 7,3 & 3,1 & $\mathbf{T} 5^{(3)}$ & 150 & 65 & 70 \\
\hline \multirow[t]{2}{*}{ Cachoeirinha } & $2004 / 05$ & 5,9 & 8,9 & 3,0 & $\mathrm{~T} 4$ & 120 & 50 & 60 \\
\hline & $2005 / 06$ & 5,0 & 8,6 & 3,6 & $\mathbf{T 4}$ & 150 & 65 & 70 \\
\hline \multirow[t]{2}{*}{ S. A. Patrulha } & $2004 / 05$ & 6,2 & 9,3 & 3,1 & $\mathbf{T} 4$ & 120 & 50 & 60 \\
\hline & $2005 / 06$ & 7,1 & 10,6 & 3,5 & T5 & 150 & 65 & 70 \\
\hline Restinga Seca & $2005 / 06$ & 6,5 & 9,2 & 2,7 & T5 & 150 & 65 & 70 \\
\hline \multirow{2}{*}{ Cachoeira Sul } & $2004 / 05$ & 5,7 & 8,7 & 3,0 & T5 & 120 & 50 & 70 \\
\hline & $2005 / 06$ & 7,4 & 10,5 & 3,1 & T5 & 150 & 65 & 70 \\
\hline Uruguaiana 1 & $2005 / 06$ & 7,7 & 9,9 & 2,1 & $\mathbf{T} \mathbf{2}^{(1)}$ & 140 & 65 & 50 \\
\hline Uruguaiana 2 & $2005 / 06$ & 8,4 & 11,5 & 3,1 & T5 & 140 & 65 & 50 \\
\hline Dom Pedrito 1 & $2005 / 06$ & 8,7 & 12,6 & 3,9 & $\mathbf{T 4}$ & 150 & 65 & 50 \\
\hline Dom Pedrito 2 & $2005 / 06$ & 9,1 & 11,4 & 2,3 & $\mathrm{~T} 4$ & 140 & 65 & 50 \\
\hline Média & $2004 / 06$ & 6,5 & 9,7 & 3,2 & & 138 & 60 & 62 \\
\hline
\end{tabular}

(1) Para atingir até 6,0 kg ha ${ }^{-1}{ }^{(2)}$ Para atingir 9,0-12,0 kg ha ${ }^{-1}{ }^{(3)}$ Para atingir $>12,0 \mathrm{~kg} \mathrm{ha}^{-1}$.

não trocável (solos esmectíticos) e estrutural (feldspatos e micas), como reportado por Castilhos et al. (2002) e Fraga et al. (2009), cabe ressaltar que a produtividade de grãos dos experimentos na época de realização dos trabalhos (décadas de 1980 e 1990) era bastante inferior aos níveis de produtividade obtidos no presente trabalho.

A falta de concordância entre a produtividade almejada e a obtida (Figuras 1 e 2) deve-se também às quantidades de $\mathrm{N}, \mathrm{P}_{2} \mathrm{O}_{5}$ e $\mathrm{K}_{2} \mathrm{O}$ adicionadas por tonelada de grãos a mais a ser produzida (CQFS RS/ SC, 2004; SOSBAI, 2005). Estas quantidades (10, 5 e $3,3 \mathrm{~kg} \mathrm{ha}^{-1}$, respectivamente para $\mathrm{N}, \mathrm{P}_{2} \mathrm{O}_{5}$ e $\mathrm{K}_{2} \mathrm{O}$ ) representam somente a reposição desses nutrientes exportados pelos grãos. Isso indica que, além de serem insuficientes para os incrementos de produtividade almejados, as doses recomendadas podem estar desequilibradas, sobretudo em relação ao K, por sua alta demanda pelo arroz, pela baixa quantidade exportada pelos grãos e por sua instabilidade no sistema solo-planta. Scivittaro \& Machado (2004) chamam a atenção para a importância da reposição do $\mathrm{K}$ absorvido pela cultura e sugerem o uso de fórmulas mais concentradas nesse nutriente e a manutenção da palhada na lavoura, que pode ser capaz de restituir ao solo em torno de $70 \%$ do $\mathrm{K}$ total absorvido. Além disso, esses pesquisadores enfatizam que a maior resposta a potássio quando a adubação de $\mathrm{N}$ é aumentada deve-se à interação entre esses nutrientes, conforme observado por Eberhardt et al. (1995). O IRRI, por sua vez, recomenda a adição de $30 \mathrm{~kg} \mathrm{ha}{ }^{-1}$ de $\mathrm{K}_{2} \mathrm{O}$ por tonelada adicional de grãos a ser produzida no caso de haver pouca contribuição de resíduos da cultura anterior (1,0-2,0 $\left.\mathrm{Mg} \mathrm{ha}^{-1}\right)$, que pode ser reduzida sucessivamente para $15 \mathrm{~kg} \mathrm{ha}^{-1}$ no caso de aumento desses resíduos até 4,0-5,0 $\mathrm{Mg}_{\text {ha-1 }}$ (Witt et al., 2007).
Os resultados do presente trabalho indicam que, além de melhor ajuste nas doses, a estratégia de adubação para o arroz irrigado utilizado no Sul do Brasil poderia ser voltada para expectativas de incremento de produtividade e não somente para expectativas de produtividade, conforme indicado pelo International Rice Research Institute (IRRI), International Plant Nutrition Institute (INPI) e International Potash Institute (IPI) em países asiáticos (Witt et al., 2007).

\section{CONCLUSÕES}

1. As respostas do arroz irrigado à adubação, quando cultivado dentro dos preceitos do manejo integrado da cultura, são consistentes e de alto retorno econômico nos diferentes locais e safras.

2. As recomendações de adubação para diferentes expectativas de produtividade para o arroz irrigado não atendem às expectativas de produtividade almejadas, pois dependem das condições edafoclimáticas de cada local.

\section{LITERATURA CITADA}

AGROLINK. Cotações de produtos agrícolas: Consulta ao preço pago ao produtor pelo Arroz Tipo 1 Longo Fino no RS. Disponível em:<http://www.agrolink.com.br/cotacoes/ index.asp>. Acesso em: 15 jan. 2007.

ANGHINONI, I.; GENRO JUNIOR, S.A.; MARCOLIN, E. \& MACEDO, V.R.M. Novas recomendações de adubação e de calagem para o arroz irrigado. Cachoeirinha, IRGA, 2005. 32p. (Boletim Técnico, 2) 
CASTILHOS, R.M.V.; MEURER, E.J.; KÄMPF, N. \& PINTO, L.F.S. Mineralogia e fontes de potássio em solos no Rio Grande do Sul cultivados com arroz irrigado. R. Bras. Ci. Solo, 26:579-587, 2002.

COMISSÃO DE FERTILIDADE DO SOLO - CFS RS/SC. Recomendações de adubação e calagem para os Estados do Rio Grande do Sul e Santa Catarina. 3.ed. Passo Fundo, SBCS Núcleo Regional Sul/Embrapa-CNPT, 1995. 223p.

COMISSÃO DE QUÍMICA E FERTILIDADE DO SOLO CQFS RS/SC. Manual de adubação e de calagem para os Estados do Rio Grande do Sul e de Santa Catarina. 10.ed. Porto Alegre, Sociedade Brasileira de Ciência do Solo, 2004. 400p.

CONAB. 2007. Sexto levantamento de avaliação de safra 2006/ 2007: Estimativas de área, produção e produtividade. Ministério da Agricultura, Pecuária e Abastecimento, 2007. 24p. Disponível em: <http://www.conab.gov.br/conabweb/ download/safra/6levsafra.pdf $>$. Acesso em: 6 jul. 2007.

EBERHARDT, D.S.; BACHA, R.E. \& STUCKER, H. Níveis de $\mathrm{N}$ e potássio para o arroz irrigado, sistema pré-germinado. In: REUNIÃO DA CULTURA DO ARROZ IRRIGADO, 21., Porto Alegre. Anais. Porto Alegre, IRGA, 1995. p.180183 .

FRAGA, T.I.; GENRO JR. S.A.; INDA, A.V. \& ANGHINONI, I. Suprimento de potássio e mineralogia de solos alagados som cultivos sucessivos de arroz. R. Bras. Ci. Solo, 33:497506, 2009.

GENRO JUNIOR, S.A.; ANGHINONI, I.; MARCOLIN, E. \& MACEDO, V.M. Eficiência das recomendações de adubação para o arroz irrigado no Rio Grande do Sul. In: CONGRESSO SUL-BRASILEIRO DO ARROZ IRRIGADO, 4., Santa Maria, 2005. Anais... Santa Maria, SOSBAI, 2005. v.1. p.404-406.

GENRO JUNIOR, S.A.; SCHOENFELD, R.; MARCOLIN, E. \& MACEDO, V.R.M. Resposta do arroz irrigado à aplicação de doses de potássio em solos com diferentes CTCs. In: CONGRESSO BRASILEIRO DE ARROZ IRRIGADO, 5., Pelotas, 2007. Anais... Pelotas, SOSBAI, 2007. p.583-585.

INSTITUTO RIO-GRANDENSE DO ARROZ - IRGA. Equipe de Política Setorial. Dados de Safra. Série Histórica da área Plantada, Produção e Rendimento. Disponível em: <http://www.irga.rs.gov.br/srquivos/ 2005020011092011.pdf>. Acesso em:10 de abr. de 2008.

LOPES, M.S.; MACEDO, V.R.M. \& CORRÊA, N.I. Curva de resposta à aplicação de $\mathrm{N}$ para cinco linhagens e três cultivares de arroz irrigado. In: CONGRESSO BRASILEIRO DE ARROZ IRRIGADO, 1.; REUNIÃO DA CULTURA DO ARROZ IRRIGADO, 22., Pelotas, 1999. Anais... Pelotas, Embrapa Clima Temperado, 1999. p.349350.

MACHADO, M.O. Adubação e calagem para a cultura do arroz irrigado no Rio Grande do Sul. Pelotas, Embrapa-CPATB, 1993. 63p. (Boletim de Pesquisa, 2)

MACHADO, M.O. \& POTTKER, D. Adubação mineral (NPK) de arroz irrigado em solos de Santa Catarina. Florianópolis, EMPASC, 1979. (Não publicado)
MACHADO, M.O. Efeitos de calcário e de N na produtividade de três safras sucessivas de arroz irrigado. In: REUNIÃO DA CULTURA DO ARROZ IRRIGADO, 12., 1983. Porto Alegre. Anais... Porto Alegre, IRGA, 1983. p.124-128.

MANUAL de adubação e calagem para os culltivos agrícolas do Rio Grande do Sul e Santa Catarina. Trigo e Soja, 56: 134, 1981.

MENEZES, V.G.; MACEDO, V.R.M. \& ANGHINONI, I. Projeto 10: Estratégias de manejo para o aumento da produtividade, competitividade e sustentabilidade da lavoura de arroz irrigado no RS. Porto Alegre, IRGA, 2004. 32p.

MIELNICZUK, J.; LUDWICK, A.E. \& BOHNEN, H. Recomendações de adubo e calcário para os solos e culturas do Rio Grande do Sul. Porto Alegre, Universidade Federal do Rio Grande do Sul, 1969. 29p. (Boletim Técnico, 2)

NORMAN, R.J.; WILSON JR, C.E. \& SLATON, N.A. Soil fertilization and mineral nutrition in U.S. mechanized rice culture. In: SMITH, C. W. \& DILDAY, R. H., eds. Rice: Origin, history, technology, and production. New Jersey, John Wiley \& Sons, 2002. p.331-411.

PINTO, L.F.S.; LAUS NETO, J.A. \& PAULETTO, E.A. Solos de várzea do Sul do Brasil. In: GOMES, A.S. \& MAGALHÃES JR, A.M., eds. Arroz irrigado no Sul do Brasil. Brasília, Embrapa Informação Tecnológica, 2004. p.75-96.

RICECHECK. Recommendations: A guide to objective rice crop management for improving yield, grain quality and profits and for economic and environmental sustainability. NSW Agriculture and BIRDC/Rice Research \& Development Committee, 2007. 20p.

SOCIEDADE SUL-BRASILEIRA DE ARROZ IRRIGADO SOSBAI. Recomendações técnicas da pesquisa para o Sul do Brasil. Itajaí, 2003. 126p.

SOCIEDADE SUL-BRASILEIRA DE ARROZ IRRIGADO SOSBAI. Recomendações técnicas da pesquisa para o Sul do Brasil. Santa Maria, 2005. 159p.

SCIVITTARO, W.B.; GOMES, A.S. \& FERREIRA, L.H.G. Otimização do uso de fertilizantes nas lavouras de arroz no RS. In: MAGALHÃES JR., A.R. \& GOMES, A.S. Arroz irrigado: Melhoramento genético, manejo do solo e da água e prognóstico climático. Pelotas, Embrapa Clima Temperado, 2003. p.35-48 (Embrapa Clima Temperado Documentos, 113)

SCIVITTARO, W.B. \& MACHADO, M.O. Adubação e calagem para a cultura do arroz irrigado. In: GOMES, A.S. \& MAGALHÃES JR., A.M. Arroz irrigado no Sul do Brasil. Brasília, Embrapa Informação Tecnológica, 2004. p.259303.

SIQUEIRA, O.J.F.; SCHERER, E.E.; TASSINARI, G.; ANGHINONI, I.; PATTELA, J.F.; TEDESCO, M.J.; MILAN, P.A. \& ERNANI, P.R. Recomendação de adubação e calagem para os Estados do Rio Grande do Sul e Santa Catarina. Passo Fundo, Embrapa-CNPT, 1987. 100p.

STRECK, E.V.; KAMPF, N.; SIMÃO, R. \& DINIZ, D. Solos do Rio Grande do Sul. 2.ed. Porto Alegre, Emater-RS, 2008. 222p. 
TABELAS de adubação corretiva e adubação de manutenção para os solos e culturas dos estados do Rio Grande do Sul e Santa Catarina. Porto Alegre: UFRGS-Faculdade de Agronomia-Departamento de Solos, 1973. 11p.

TERRES, A.L.S.; FAGUNDES, P.R.R.; MACHADO, M.O.; MAGALHÃES JR., A.M. \& NUNE, D.D.M. Melhoramento genético do arroz irrigado. In: GOMES, A.S. \& MAGALHÃES JR., A.M., eds. Arroz irrigado no Sul do Brasil. Brasília, Embrapa Informação Tecnológica, 2004. p.259-303.

VAHL, L.C. O fósforo na cultura do arroz irrigado. In: YAMADA, T. \& ABDALLA, S.R., eds. SIMPÓSIO DE FÓSFORO NA AGRICULTURA BRASILEIRA. Piracicaba, Potafós, 2004. p.419-434.
WALKER, T.W. \& STREET, J.E. Rice fertilization. Starkville, Mississipi State University Extension Service Publication, 2003. 4p. (Information Sheet, 1341)

WITT, C.; BURESH, R. J.; PENG, S.; BALASUBRAMANIAN, V. \& DOBERMANN, A. Nutrient management. In: FAIRHURST, T.H.; WITT, C.; BURESH, R.L. \& DOBERMANN, A., eds. Rice: A practical guide to nutrient management. 2.ed. Los Baños, International Rice Research Institute (IRRI), Philippines, International Plant Nutrition Institute (IPNI) and International Potash Institute (IPI), 2007. p.1-43. 